\title{
Ranitidine reduced clinically important gastrointestinal bleeding in patients who required mechanical ventilation
}

\author{
Cook D, Guyatt G, Marshall F, et al, for the Canadian Critical Care Trials Group. A comparison of sucralfate and \\ ranitidine for the prevention of upper gastrointestinal bleeding in patients requiring mechanical \\ ventilation. $N$ Engl f Med 1998 Mar 19;338:791-7.
}

\section{Question}

In patients who require mechanical ventilation, what is the efficacy and safety of sucralfate compared with ranitidine for preventing upper gastrointestinal bleeding?

\section{Design}

Randomised, triple blind, controlled trial with follow up to hospital discharge or death.

\section{Setting}

16 intensive care units (ICUs) in Canada.

\section{Patients}

1200 patients (mean age $59 \mathrm{y}, 60 \%$ men) who were admitted to ICUs and were expected to require mechanical ventilation for $\geqslant 48$ hours. Exclusion criteria were gastrointestinal bleeding or pneumonia at admission, gastrectomy, poor prognosis, previous randomisation in a trial, or previous open label prophylactic treatment. Follow up was complete.

\section{Intervention}

Patients were allocated to intravenous bolus ranitidine (Zantac, Glaxo Wellcome), 50 mg every 8 hours ( $=596)$, or sucralfate (Sulcrate, Hoechst Marion Roussel) suspension through a nasogastric tube or given orally, 1 g every 6 hours ( $\mathrm{n}=604)$. Ranitidine doses were adjusted for patients with creatinine clearance rates of $25-50 \mathrm{ml} / \mathrm{minute}$ ( $50 \mathrm{mg}$ every $12 \mathrm{~h}$ ) or $<25 \mathrm{ml} /$ minute (50 mg every $24 \mathrm{~h}$ ) and for patients dependent on dialysis ( $50 \mathrm{mg}$ every $12 \mathrm{~h}$ ).

\section{Main outcome measures}

Clinically important gastrointestinal bleeding, ventilator associated pneumonia, length of stay in the ICU, and mortality.

\section{Main results}

Analysis was by intention to treat. More patients allocated to sucralfate than to ranitidine had clinically important bleeding $(p=0.02)$ (table). No differences existed between groups for ventilator associated pneumonia, mortality (table), or length of stay in the ICU (median 9 days for both groups).

\section{Conclusions}

In patients who required mechanical ventilators, ranitidine led to less gastrointestinal bleeding than did sucralfate. Ventilator associated pneumonia, mortality, and length of stay in the ICU did not differ between treatment groups.

Sources of funding: Medical Research Council of Canada and Hoechst Marion Roussel.

For correspondence: Dr D Cook, Department of Medicine, St foseph's Hospital, 50 Charlton Avenue, Hamilton, Ontario L8N 4A6, Canada. Fax +1905 5216068.

Ranitidine $v$ sucralfate in patients onmechanical ventilators *

\begin{tabular}{lllll}
\hline Outcome & Ranitidine & Sucralfate & RRI (95\% CI) & NNT (CI) \\
\hline GI bleeding & $1.7 \%$ & $3.8 \%$ & $56 \%(10$ to 79$)$ & $47(25$ to 339) \\
$\begin{array}{l}\text { Outcomes } \\
\text { Ventilator }\end{array}$ & Ranitidine & Sucralfate & RRI (CI) & NNH \\
$\begin{array}{l}\text { associated } \\
\quad \text { pneumonia }\end{array}$ & $19.1 \%$ & $16.2 \%$ & $18 \%(-8$ to 51$)$ & NS \\
Mortality & $23.5 \%$ & $22.8 \%$ & $3 \%(-16$ to 26$)$ & NS \\
\hline
\end{tabular}

${ }^{\star} \mathrm{GI}=$ gastrointestinal; $\mathrm{NS}=$ not significant; $\mathrm{RRI}=$ proportional decrease in rates of bad outcomes between ranitidine and sucralfate groups; NNT=number of patients who must receive ranitidine to achieve 1 additional good outcome; RRI=proportional increase in rates of bad outcomes between ranitidine and sucralfate; $\mathrm{NNH}=$ number of patients who, if they received ranitidine, would lead to 1 additional person being harmed.

\section{Commentary}

In the early days of intensive care rates of overt gastrointestinal bleeding were high and it soon became widely accepted that some form of prophylaxis was required. This view was supported by randomised trials indicating that the incidence of clinically important bleeding can be reduced by administration of either $\mathrm{H}_{2}$ receptor antagonists or antacids. ${ }^{1}$ Observational studies, however, suggested that the higher gastric $\mathrm{pH}$ consequent on such treatment was associated with bacterial overgrowth in the stomach, tracheobronchial colonisation and nosocomial pneumonia. The publication of a randomised trial indicating that the cytoprotective agent sucralfate was associated with a trend toward a lower incidence of ventilator associated pneumonia $(\mathrm{VAP})^{2}$ had a considerable influence on clinical practice, as did studies documenting that with modern intensive care the incidence of clinically important bleeding is low, especially in those receiving enteral nutrition. Intensive care clinicians have therefore been faced with two fundamental questions: which patients, if any, should receive prophylaxis against gastrointestinal bleeding and which agent should be used?
Given this uncertainty the publication of the large (1200 patients), prospective, randomised, controlled trial by Cook et al comparing the effects of sucralfate and ranitidine on the incidence of gastrointestinal bleeding and VAP in mechanically ventilated patients is welcome.

In contrast to the findings of a previous meta-analysis performed by the same group $^{1}$ the results suggest that patients receiving ranitidine have a significantly lower risk of gastrointestinal bleeding than those given sucralfate. Indeed the incidence of bleeding in the sucralfate group in 
(continued from page 10) this trial (3.8\%) was very similar to the $3.7 \%$ incidence observed in untreated mechanically ventilated patients ${ }^{3}$ and the authors estimate that only 50 patients would need to be treated with ranitidine instead of sucralfate to prevent one episode of gastrointestinal bleeding. Importantly, in keeping with the results of other more recent trials ${ }^{1}$ there was no significant difference in the incidence of VAP (diagnosed using particularly rigorous criteria).

A number of factors complicate interpretation of these findings. Although the authors used rigorous criteria for the diagnosis of "clinically important" gastrointestinal haemorrhage the decision to perform endoscopy was left to the discretion of the intensive care specialist; only $17 \mathrm{pa}$ tients underwent endoscopy and only 14 (4 in the ranitidine group and 10 in the sucralfate group) had documented oesophageal, gastric or duodenal ulcers/ erosions, the source of bleeding remaining unknown for 19 of 33 patients. Post hoc analysis of those with documented upper gastrointestinal lesions did, however, yield results consistent with the main finding of the study. In each group around $70 \%$ of patients received enteral nutrition which is known to reduce the incidence of gastrointestinal bleeding, as well as potentially interfering with the protective action of sucralfate and, because it raises gastric $\mathrm{pH}$, perhaps making the administration of ranitidine superfluous. The authors have, however, subsequently confirmed that the type, timing and tolerance of feeding were similar in the two groups ${ }^{4}$ but did not reveal the relation between enteral nutrition and bleeding. Finally neither the duration of prophylaxis prior to the episodes of gastrointestinal bleeding nor the incidence of coagulopathy are reported.

Although there was no difference in the length of ICU stay, the duration of intubation or mortality between the two groups, and despite the non-significant trend to more VAP's in patients given ranitidine, many clinicians are likely to conclude that ranitidine should be preferred to sucralfate for prophylaxis against gastrointestinal bleeding in long stay mechanically ventilated patients. This study leaves the important question of which patients should receive prophylaxis unanswered.

C J HINDS

$S$ N FLETCHER

Department of Intensive Care, St Bartholomew's Hospital, West Smithfield, London EC1A 7BE, UK

1 Cook DJ, Reeve BK, Guyatt GH, et al. Stress ulcer prophylaxis in critically ill patients. Resolving discordant meta-analyses. $7 A M A$ 1996;275:308-429.

2 Driks MR, Craven DE, Celli BR, et al. Nosocomial pneumonia in intubated patients given sucralfate as compared with antacids or histamine type 2 blockers. The role of gastric colonization. N Engl f Med 1987;317:1376-82.

3 Cook DJ, Fuller HD, Guyatt GH, et al. Risk factors for gastrointestinal bleeding in critically ill patients. N Engl F Med 1994;330:428-9.

4 Cook D, Guyatt G, Leasa D. Prevention of gastrointestinal bleeding during mechanical ventilation [letter]. N Engl f Med 1998;339:267-8. 